\title{
ROLUL DIPLOMAŢIEI CULTURALE ÎN RELAŢIILE INTERNAŢIONALE. STUDIU DE CAZ PORTUGALIA
}

\author{
Mădălina MAZĂRE* \\ The role of cultural diplomacy in international relations. \\ Study case - Portugal
}

\begin{abstract}
The present paper aims to briefly present the main elements of cultural diplomacy and their role in international relations, analysing the case of Portugal. To explain the theoretical aspects of cultural diplomacy, the text is organized into four sub-chapters, respectively What is cultural diplomacy? The objectives of cultural diplomacy, Cultural diplomacy in the EU context, The importance of cultural diplomacy in external relations. This first chapter aims to highlight the effects of cultural diplomacy on society and to outline the importance of its use in the current context. To describe cultural diplomacy in Portugal, the text is organized into three sub-chapters, namely the Evolution of Cultural Diplomacy in Portuguese Space, Coordinating Institutions and Organizations, Main Elements of Cultural Diplomacy in Portugal. This case study has the role of analysing the elements of cultural diplomacy in Portugal and at the same time to observe its effects over the years on the country's development on several levels.
\end{abstract}

Keywords: international relations, cultural diplomacy, political studies, soft power, international integration and cooperation, intercultural dialogue

\section{Diplomaţia culturală. Aspecte teoretice}

\subsection{Ce este diplomaţia culturală?}

Pentru a înţelege conceptul de diplomaţie culturală se va efectua o explicaţie individuală a cuvintelor componente. Dicţionarul Explicativ al Limbii Române oferă următoarele explicaţii cuvintelor "diplomaţie", respectiv "cultură":

- diplomaţia reprezintă o activitate desfășurată de un stat prin reprezentanții săi peste graniță pentru a asigura legături reciproce cu celelalte state și a realiza obiectivele politicii sale externe şi ansamblu de metode și de procedee folosite în domeniul relațiilor internaţionale dintre state.

\footnotetext{
*Universitatea "Titu Maiorescu", 22 Strada Dâmbovnicului Tineretului, București, 040441 (madalinamazare@gmail.com).
} 
- cultura reprezintă totalitatea valorilor materiale și spirituale create de omenire și a instituțiilor necesare pentru comunicarea acestor valori şi ansamblu de activităţi și modele de comportament proprii unui grup social dat, transmisibile prin educație.

In lucrarea "The new public diplomacy. Soft power in international relations", Melissen J. definește diplomaţia culturală ca fiind un schimb de idei, informaţii, artă şi alte aspecte culturale între naţiuni şi populaţia lor, pentru a promova înţelegerea mutuală; reprezintă o componentă importantă a diplomaţiei publice, care cuprinde practic tot ceea ce o ţară face pentru a se explica lumii întregi. Diplomaţia culturală se referă la rolul pe care îl au factorii culturali in relaţiile internaţionale şi include arta,expoziţiile culturale, programele educaţionale, mobilităţile, literatura, televiziunea, programele culturale şi altele.

\subsection{Obiectivele diplomaţiei culturale}

„Obiectivul principal al diplomaţiei culturale este de a influenţa pozitiv opinia publică şi elitele de opinie dintr-un stat străin."1 Consiliul Ştiinţific Olandez pentru Politica Guvernamentală (Netherlands Scientific Council for Government Policy, 1987) defineşte, în lucrarea numită Cultură şi diplomaţie trei obiective fundamentale ale diplomaţiei culturale care poți fi adoptate de fiecare stat: promovarea înţelegerii mutuale, dezvoltarea prestigiului unei ţări şi protejarea identităţii culturale. Aceste obiective se pot obţine prin intermediul a diferite instrumente, cum ar fi: programe de schimburi culturale, mobilităţi,burse de studiu, vizite culturale, promovarea evenimentelor culturale internaţionale, promovarea limbii, conferinţe şi publicaţii internaţionale.

\subsection{Diplomaţia culturală în contextul UE}

Cultura poate fi un factor cheie pentru parteneriatele internaţionale. Comisia Europeană şi Înaltul Reprezentant al Uniunii pentru afaceri externe şi politica de securitate au prezentat Strategia pentru relaţiile culturale internaţionale prin care doresc să promoveze cooperarea în domeniul cultural între ţările partenere şi Uniunea Europeană, punându-se accentul pe ordine globală bazată pe pace, pe statul de drept, pe libertatea de exprimare, pe înțelegerea reciprocă și pe respectarea valorilor fundamentale.

„Cultura trebuie să facă parte integrantă din politica noastră externă. Cultura este un instrument puternic pentru a crea punţi de legătură între

\footnotetext{
${ }^{1}$ Saddiki, Said, El papel de la diplomacia cultural en las relaciones internacionales, Revista Cidob d'Afers, Internacionals 88, p 110, accesat la 13.09.2018, disponibil la www.cidob.org
} 
oameni, în special între tineri, și pentru a consolida înțelegerea reciprocă. În același timp, ea poate fi un motor al dezvoltării economice și sociale. În fața unor provocări comune, cultura ne poate reuni pe toți - fie că suntem cetățeni ai Europei, ai Africii, ai Orientului Mijlociu sau ai Asiei - în lupta împotriva radicalizării și în construirea unei alianțe a civilizaţiilor împotriva celor care încearcă să creeze disensiuni. Iată de ce diplomația culturală trebuie să se afle în centrul relațiilor noastre cu lumea de astăzi.",2 a declarat Federica Mogherini, Înaltul Reprezentant şi vicepreşedintele Uniunii.

Este afirmat faptul că diplomaţia culturală poate aduce importante beneficii UE şi statelor care îi acorda importanţă deosebită. Dezvoltarea durabilă este susţinută de cetăţenia globală, diversitatea culturală şi dialogul intercultural. Prevenirea conflictelor poate fi realizată prin intermediul dialogului intercultural, iar integrarea refugiaţilor, combaterea evenimentelor violente şi protecţia patrimoniului mondial pot fi soluţionate prin intermediul culturii. Diplomaţia culturală şi practicarea sa diferă de la un stat la altul, fiind influenţată de "stilul şi tradiţiile diplomatice ca şi de locul pe care cultura în sine îl reprezintă în politica unei ţări." 3 În majoritatea ţărilor membre ale Uniunii Europene, diplomaţia cultural guvernamentală este asigurată de Ministerul Culturii şi Ministerul de Externe, de exemplu Institutul Cultural Francez, Consiliul Britanic, Institutul Goethe, Institutul Cultural Român. DG EAC - Directoratul General pentru Educaţie şi Cultură este ramura executivă a Uniunii Europene responsabilă pentru politica în educaţie, cultură, tineret, limbi şi sport,sprijinindu-le prin diferite proiecte şi programe, considerabile fiind Europa Creativă şi Erasmus+. DG EAC coordonează Programul Europa Creativă, care finanţează sute de programe ce sprijină artiştii, actorii, muzicienii şi alţii. Scopul activităţilor culturale este „de a promova diversitatea culturală şi dialogul intercultural, cultura ca şi catalizator pentru creativitate şi cultura europeană ca parte vitală a relaţiilor externe."4

\subsection{Importanţa diplomaţiei culturale în relaţiile externe}

J. Nye, autorul termenului "soft power", consideră diplomaţia culturală ca fiind cel mai bun exemplu de "soft power" (putere delicată), oferind posibilitatea de comunicare prin intermediul valorilor şi ideilor unei culturii, fiind în contrast cu "hard power"(putere fermă), care utilizează instrumente militare."Chiar dacă importanţi experţi ca Walter Laqueur,

\footnotetext{
2 Comisia Europeană, "O nouă strategie pentru a pune cultura în centrul relațiilor internaționale ale UE”, Comunicat de presă, Bruxelles, 8 iunie 2016

${ }^{3}$ Jora, Lucian, Diplomaţia culturală a Uniunii Europene. Aspecte funcţionale ale serviciului European de acţiune externă, Revista Ştiinţe Politice şi Relaţii Internaţionale, IX, 2, Bucureşti, 2012, p 41

${ }^{4}$ www.ec.europa.eu, accesat pe 13.09.2018
} 
George Kennan şi Thomas Pickering au discutat despre importanţa diplomaţiei culturale, în contextul actual al securităţii unui stat,diplomaţia culturală este uşor uitată deoarece este considerată prea delicată şi periferică problemelor reale de securitate."

Diplomaţia culturală este un instrument important pentru relaţiile externe, însa datorită faptului că nu produce rezultate imediate a fost "acuzată de ineficienţă şi risipă de fonduri,cu precădere în perioadele de declin economic. Aceasta poate fi evaluată doar în timp, pe parcursul procesului intervenind diferiţi factori externi care îi pot influenţa cursul stabilit." "Diversitatea culturală la scară globală are reale avantaje economice şi neeconomice, un aspect fiind faptul că încurajează inovaţia."7 Noile tehnologii de comunicaţie grăbesc procesul de globalizare şi afectează diferenţele culturale dintre ţări. Acest efect a avut impact asupra unor ţări care sunt îngrijorate de faptul că se asistă la o cultură prea globală,în sensul că se omogenizează pe zi ce trece. În Europa, diversitatea culturală este reflectată prin intermediul limbii, literaturii, artelor,arhitecturii. Limba, în mod special, este o expresie naturală şi directă a fiecărei culturi.

\section{Studiu de caz Portugalia}

\subsection{Evoluţia diplomaţiei culturale în spaţiul portughez}

Asemenea marilor puteri vestice şi Portugalia dispune de aşa numita "soft power ", prezentă nu numai în ţările vorbitoare de limba portugheză, respectiv comunitatea lusofonă, ci în întreaga lume. Prezenţa culturii şi limbii portugheze în afara graniţelor a devenit evidentă începând cu secolul $\mathrm{XV}$, cu începutul descoperirilor. Prima încercare de promovare a culturii în străinătate a început în anul 1415, în Maroc. De-a lungul timpului limba portugheză a devenit un instrument de comerţ şi comunicare internaţională, în timpul colonizărilor din Asia, Africa şi America. Diplomaţia culturală a fost practicată de-a lungul secolelor de vânzători, artişti, turişti, exploratori, practic orice persoană care şi-a promovat propria cultură într-un loc străin.

O îmbunătăţire a modului în care ţara vede diplomaţia culturală şi publică s-a produs după sfârşirea perioadei de totalitarism sub regimul lui Antonio de Oliveira Salazar, după 1974 şi mai ales odată cu intrarea în

\footnotetext{
${ }^{5}$ Melissen, Jan, "The new public diplomacy. Soft power in international relations.", Palgarve Macmillan, New York, 2005, p 163

${ }^{6}$ Jora, Lucian, "Diplomaţia culturală a Uniunii Europene. Aspecte funcţionale ale serviciului European de acţiune externă", Revista Ştiinţe Politice şi Relaţii Internaţionale, IX, 2, Bucureşti, 2012, p 42

${ }^{7}$ Feigenbaum, Harvey B., "Globalization and cultural diplomacy", The George Washington University, Center for arts and culture, Washington, 2001, p 37
} 
Comunitatea Economică Europeană în anul 1986.De când s-a înfiinţat Ministerul Culturii în anul 1995, au fost menţinute prioritare câteva politici culturale, printre care şi protejarea patrimoniului naţional. Începând cu anul 2009 ,s-au axat şi pe alte elemente, cum ar fi limba portugheză, industriile culturale şi creative,promovarea internaţională a artiştilor portughezi şi instituţiilor culturale. Totodată se poate aminti şi faptul că politica culturală a fost restricţionată de bugetul limitat determinat de criza financiară globală.

În anii '90 Portugalia a început să desfăşoare proiecte relevante pentru a-şi construi imaginea de ţară în străinătate, de exemplu Europalia în 1991, Lisabona Capitală Europeană a Culturii în 1994, prezenţa la World Exibition Expo în 1998, Porto Capitală Europeană a Culturii în 2001, Campionatul European de fotbal în 2004, etc.

\subsection{Instituţii şi organizaţii coordonatoare}

Politica culturală în Portugalia este remisa de Ministerul culturii, fiind bazată în principal pe modelul centralizat. Acesta defineşte cultura ca fiind un element indispensabil în dezvoltarea capacităţilor intelectuale şi calităţii vieţii, instrument cheie pentru o înţelegere critică a lumii reale. Alături de serviciile periferice administrate direct de către stat, există şi cinci Departamente Regionale de Cultură (Nord, Centru, Lisabona, Alentejo şi Algarve). Institutul Camões, înfiinţat oficial în anul 1992, joacă un rol cheie în diplomaţia culturală a Portugaliei. Această instituţie publică, independentă din punct de vedere administrativ şi financiar, operează în domeniul culturii şi învăţământului. Misiunea sa este de a implementa politici de promovare a culturii şi limbii portugheze în străinătate. Coordonează iniţiativele culturale ale ambasadelor şi consulatelor portugheze prin intermediul unui plan anual de activităţi. În contextul european Institutul Camões este membru EUNIC - Uniunii Europene a Institutelor Naţionale pentru Cultură (European Union National Institutes for Culture) şi EFNIL - Federaţiei Europene a Instituţiilor Naţionale de Limbă (European Federation of National Institutions for Language). "Principalul obiectiv ale acestor instituţii este de a dezvolta identitatea europeană, element strâns conectat cu diversitatea culturală şi lingvistică şi bazat pe principiul unitate în diversitate."

Rețeaua WHPO - World Heritage of Portuguese Origin - a fost înfiinţată în octombrie2010 şi este o reţea mondială de cooperare a ţărilor care au influenţe portugheze în moştenirea culturală. Există 25 de membri de pe 4 continente, Europa, Africa, Asia şi America de Sud. Proiectul include Universitatea din Coimbra, Comitetul National UNESCO,

\footnotetext{
${ }^{8}$ Teles, Ana Filipa, Portugal and Cultural Diplomacy, accesat pe 13.09.2018, disponibil la www.culturaldiplomacy.org
} 
IGESPAR (Instituto de Gestão do Património Arquitectónico e Arqueológico)şi ICOMOS Portugal (the Portuguese National Committee of the International Council on Monuments and Sites).

\subsection{Principalele elemente ale diplomaţiei culturale în Portugalia}

Limba portugheză - cooperarea culturală internaţională s-a axat pe promovarea limbii portugheze şi culturii. De aici, cooperarea dezvoltată cu ţările care au ca limbă oficială portugheza, Comunitatea Țărilor vorbitoare de Limba Portugheză. CPLP este o organizaţie internaţională care are scopul de a promova dezvoltarea socială şi economică pentru persoanele vorbitoare de limba portugheză, având lusofonia ca punct comun. Portugheza este limba oficială în Portugalia şi este vorbită de aproximativ 240 milioane de persoane în toată lumea, „fiind a cincea limbă cea mai vorbită."

Expoziţii, târguri şi festivaluri - cooperarea culturală internaţională include de asemenea expoziţiile lucrărilor de artă înalte ţări (participarea la festivaluri şi târguri internaţionale), cât şi evenimentele principale organizate în Portugalia, de exemplu Guimãraes - Capitala Europeană a Culturii în anul2012.

Educaţie - programele interculturale de educaţie sunt promovate în Portugalia pentru a informa studenţii cu privire la importanţa altor culturi şi pentru a promova dialogul intercultural. În anii ' 90 , guvernul portughez a înfiinţat şcoli în străinătate, acolo unde numărul emigranţilor era mai mare pentru a răspunde la necesităţile populaţiei, pentru a promova prin intermediul acestora cultura portugheză şi pentru a atrage elitele din acele ţări. Prima şcoală a fost înfiinţată în Luanda, Angola în anul 1994, apoi în 1998 a fost înfiinţată şcoala portugheză din Macau, 1999 şcoala din Mozambique, 2002 şcoala din Dili, Timorul de est,etc.

Mass-media - cultura portugheză este, de asemenea, promovată prin intermediul televiziunii, de exemplu: RTP International (RTP-I 1992), RTP Africa (RTP-A 1998). "Un punct slab este faptul că informaţiile ajung mai greu la audienţa nevorbitoare de limba portugheză, deoarece programele emise sunt doar în această limbă." ${ }^{10}$ Noile tehnologii s-au făcut remarcate şi în cadrul culturii şi artei, oferind suport pentru implementarea a numeroase proiecte în spaţiul virtual, de exemplu www.culturaonline.pt, site promovat de Ministerul Culturii, care permite accesul la arta şi literatura portugheză.

Constituţia țării are un întreg capitol destinat drepturilor şi îndatoririlor culturale (Articolul73-79). Articolul 78 spune că toată lumea

\footnotetext{
${ }^{9}$ www.bucareste.embaixadaportugal.mne.pt, accesat pe 13.09.2018

${ }^{10}$ Teles, Ana Filipa, Portugal and Cultural Diplomacy, accesat pe 13.09.2018, disponibil la www.culturaldiplomacy.org
} 
are dreptul de a se bucura de cultură şi creaţie şi îndatorirea de a conserva, apăra şi îmbunătăţi patrimoniul cultural.

\section{Concluzie}

După trecerea în revistă ale principalelor aspecte relaţionate cu diplomaţia culturală şi după analiza cazului Portugaliei se poate afirma faptul că pentru a avea rezultate cât mai bune în acest domeniu este necesară alocarea suficientă de fonduri astfel încât să se poată atinge obiectivele vizate. Portugalia utilizează diplomaţia culturală pentru a-şi contura o imagine favorabilă în afara ţării, utilizând aspecte de bază a culturii statului. Astfel, prin intermediul imaginii create şi relaţiilor diplomatice stabilite cu diferite state, pot apărea noi parteneriate care să influenţeze pozitiv, pe lungă durată, dezvoltarea statului din punct de vedere social,economic, politic.

Deşi diplomaţia culturală nu produce rezultate imediate, utilizarea corectă a acesteia se poate transforma într-una dintre cele mai importante "arme", mai ales in contextul actual poate produce reale îmbunătăţiri în relaţiile dintre state şi populaţiile aferente. După cum am punctat în capitolul Diplomaţia culturală. Aspecte teoretice, diplomaţia cultural constă în împărtăşirea propriilor modalităţi de expresie culturală. Dacă fiecare individ înţelege cultura şi tradiţiile celorlalte ţări, atunci situaţia de ansamblu va fi una guvernată de toleranţă şi respect.

\section{Bibliografie}

Academia Română, Dicţionarul Explicativ al Limbii Române, Editura Univers Enciclopedic Gold, Bucureşti, 2012

Comisia Europeană, O nouă strategie pentru a pune cultura în centrul relațiilor internaționale ale UE, Comunicat de presă, Bruxelles, 8 iunie 2016

Feigenbaum, Harvey B., Globalization and cultural diplomacy, The GeorgeWashington University, Center for arts and culture, Washington, 2001

Jora, Lucian, Diplomația culturala a Uniunii Europene. Aspecte funcționale ale serviciului European de acțiune externa, Revista Științe Politice si RelatiiInternationale, IX, 2, Bucuresti, 2012)

Melissen, Jan, The new public diplomacy. Soft power in international relations,Palgarve Macmillan, New York, 2005

Nye J., The Paradox of American Power, Oxford University Press, Oxford,2002 
Nye, Joseph. Soft Power - The Means to Success in World Politics. Public Affairs, New York 2004

Saddiki, Said, El papel de la diplomacia cultural en las relaciones internacionales, Revista Cidob d'Afers, Internacionals 88, disponibil la www.cidob.org

www.bucareste.embaixadaportugal.mne.pt

Compendium of Cultural Policies and Trends in Europe, 13th edition, 2012, accesat pe 13.09.2018, disponibil la www.culturalpolicies.net

www.culturaonline.pt

www.ec.europa.eu

www.instituto-camoes.pt

www.portaldacultura.gov.pt,

Teles, Ana Filipa, Portugal and Cultural Diplomacy, disponibil la www.culturaldiplomacy.org 